\section{Interleukin-4 as an emerging therapeutic target for IgG4-related disease}

We read the manuscript reported by Simpson et al with great interest. ${ }^{1}$ They showed remarkable effectiveness of dupilumab, a monoclonal antibody targeting the interleukin-4 (IL-4) receptor alpha, in immunoglobulin G4-related disease (IgG4-RD) complicated with retroperitoneal fibrosis for the first time. Considering the frequent relapse in patients with IgG4-RD during glucocorticoid tapering and the difficulty in glucocorticoid withdrawal, ${ }^{2}$ it is of great value that their patient could discontinue prednisone within 2 months after starting dupilumab and even remain stable without any relapse for 12 months. ${ }^{1}$ They also showed no significant adverse effects of dupilumab for the duration. We have previously revealed that IL-4 plays an important role in the pathogenesis of IgG4-RD. ${ }^{3-5}$ In particular, IL-4-producing follicular helper $\mathrm{T}$ cells contribute to IgG4 class-switching and plasmablast differentiation in the disease. ${ }^{3-5}$ The case reported by Simpson et al connects the basic research findings with the translational application and sheds light on the possibility of dupilumab as a glucocorticoid-sparing and relapse-suppressing agent in patients with IgG4-RD. We are pleased to read their great report and would like to ask several questions for clarification.

The first is regarding the diagnosis of IgG4-RD. Antineutrophil cytoplasmic antibody (ANCA)-associated vasculitis can mimick IgG4-RD as patients with ANCA-associated vasculitis frequently show elevated levels of serum IgG4 and IgG4-positive B-cell infiltration along with fibrosis in the inflamed tissues, whereas neutrophilic inflammation, granulomatous changes, necrotising lesions and multinucleated giant cells are not usual findings in IgG4-RD. ${ }^{6}$ Therefore, the findings of serum IgG4 levels and pathological IgG4-positive B-cell infiltration might not be sufficient for differentiating the two diseases. And, while retroperitoneal fibrosis is one of the major organ involvements in patients with IgG4-RD, ANCA-positive retroperitoneal fibrosis has also been reported. ${ }^{6}$ Clinical characteristics of ANCA-positive retroperitoneal fibrosis are very similar to those of IgG4-RD in terms of elderly and male predominance. Collectively, careful exclusion of ANCA-associated vasculitis is needed before the final diagnosis with IgG4-RD. In the context, we would like to ask if the patient had any indication of ANCA-associated vasculitis rather than IgG4-RD such as fever, elevated blood neutrophil counts and serum $\mathrm{C}$ reactive protein levels, and ANCA positivity as well as neutrophilic infiltration, granulomatous formation, necrotising vasculitis and multinucleated giant cells in the prostate tissues. Of note, the similar case of granulomatosis with polyangiitis complicated with rhinitis, retroperitoneal fibrosis and pathologically confirmed granulomatous prostatitis along with PR3-ANCA positivity was reported. ${ }^{7}$ Furthermore, prostatitis is the most common extrarenal urogenital manifestation of granulomatosis with polyangiitis. ${ }^{8}$

Second, the authors noted that the patient also had the eye swelling and parotitis at initial presentation, however, it is unclear whether those manifestations were derived from IgG4RD. We are curious about the laterality of his lacrimal and parotid gland enlargement and the improvement in those organs after dupilumab therapy.

Third, why did the patient get a prostate biopsy for pathological confirmation of IgG4-RD? Was the enlargement of prostate symptomatic or just found by images? In addition, the information about whether tertiary lymphoid organs (also known as 'ectopic lymphoid organs', 'ectopic germinal centres' or 'lymphoid aggregates') were observed in the prostate biopsy specimen is important as those lymphoid organ-like structures frequently observed in the lesions of IgG4-RD are associated with IL-4-producing follicular helper T-cell infiltration. ${ }^{69}$

We believe that answers to our questions can further confirm the promising prospects of dupilumab as the treatment of IgG4RD. Further randomised studies are warranted to determine the benefits of dupilumab in terms of its glucocorticoid-sparing effect and reduction of relapse or even remission induction in patients with IgG4-RD.

\section{Mitsuhiro Akiyama $\odot^{\circ}$, Yuko Kaneko, Tsutomu Takeuchi}

Division of Rheumatology, Department of Internal Medicine, Keio University School of Medicine, Shinjuku-ku, Tokyo, Japan

Correspondence to Dr Yuko Kaneko, Division of Rheumatology, Department of Internal Medicine, Keio University School of Medicine, 35 Shinanomachi, Shinjuku-ku, Tokyo, Japan; ykaneko.z6@keio.jp

Contributors MA, YK and TT: wrote and discussed the manuscript. All authors approved the final version of the manuscript.

Funding The authors have not declared a specific grant for this research from any funding agency in the public, commercial or not-for-profit sectors.

Competing interests MA: reports no conflicts of interest relevant to this article. YK: has received grants or speaker fees from AbbVie, Astellas, Ayumi, Bristol-Myers Squibb, Chugai, Eisai, Eli Lilly, Hisamitsu, Jansen, Kissei, Pfizer, Sanofi, Takeda, TanabeMitsubishi and UCB. TT: has received research grants or speaking fees from Astellas Pharma Inc, Bristol-Myers K.K., Chugai Pharmaceutical Co, Ltd, Daiichi Sankyo Co, Ltd, Takeda Pharmaceutical Co, Ltd, Teijin Pharma Ltd, AbbVie GK, Asahi Kasei Pharma Corp., Mitsubishi Tanabe Pharma, Astra Zeneca K.K., Eli Lilly Japan K.K., Novartis Pharma K.K., AbbVie GK, Nippon Kayaku Co Ltd, Janssen Pharmaceutical K.K., Taiho Pharmaceutical Co, Ltd, and Pfizer Japan Inc.

Patient consent for publication Not required.

Provenance and peer review Not commissioned; internally peer reviewed. (c) Author(s) (or their employer(s)) 2020. No commercial re-use. See rights and permissions. Published by BMJ.

\section{Check for updates}

To cite Akiyama M, Kaneko Y, Takeuchi T. Ann Rheum Dis Epub ahead of print: [please include Day Month Year]. doi:10.1136/annrheumdis-2020-216961

Received 7 January 2020

Accepted 10 January 2020

Ann Rheum Dis 2020;0:1. doi:10.1136/annrheumdis-2020-216961

\section{ORCID iD}

Mitsuhiro Akiyama http://orcid.org/0000-0001-5075-8977

\section{REFERENCES}

1 Simpson RS, Lau SKC, Lee JK. Dupilumab as a novel steroid-sparing treatment for lgG4related disease. Ann Rheum Dis 2019. doi:10.1136/annrheumdis-2019-216368

2 Sasaki T, Akiyama M, Kaneko Y, et al. Risk factors of relapse following glucocorticoid tapering in IgG4-related disease. Clin Exp Rheumatol 2018;112:186-9.

3 Akiyama M, Yasuoka H, Yoshimoto K, et al. Interleukin-4 contributes to the shift of balance of $\lg \mathrm{G}$ subclasses toward $\lg \mathrm{G} 4$ in $\lg \mathrm{G} 4$-related disease. Cytokine 2018;110:416-9.

4 Akiyama M, Yasuoka H, Yamaoka K, et al. Enhanced IgG4 production by follicular helper $2 \mathrm{~T}$ cells and the involvement of follicular helper $1 \mathrm{~T}$ cells in the pathogenesis of IgG4-related disease. Arthritis Res Ther 2016;18:167.

5 Akiyama M, Suzuki K, Yamaoka K, et al. Number of circulating follicular helper $2 \mathrm{~T}$ cells correlates with lgG4 and interleukin-4 levels and Plasmablast numbers in IgG4-related disease. Arthritis Rheumatol 2015;67:2476-81.

6 Akiyama M, Takeuchi T. Igg4-Related disease: beyond glucocorticoids. Drugs Aging 2018;35:275-87.

7 ter Maaten JC, Franssen CF, Daenekindt AA, et al. Triple Wegener's granulomatosis in the urogenital tract. Nephron 1993;63:358-9.

8 Alba MA, Moreno-Palacios J, Beça S, et al. Urologic and male genital manifestations of granulomatosis with polyangiitis. Autoimmun Rev 2015;14:897-902.

9 Takanashi S, Akiyama M, Suzuki K, et al. Igg4-Related fibrosing mediastinitis diagnosed with computed tomography-guided percutaneous needle biopsy: two case reports and a review of the literature. Medicine 2018;97:e10935. 